
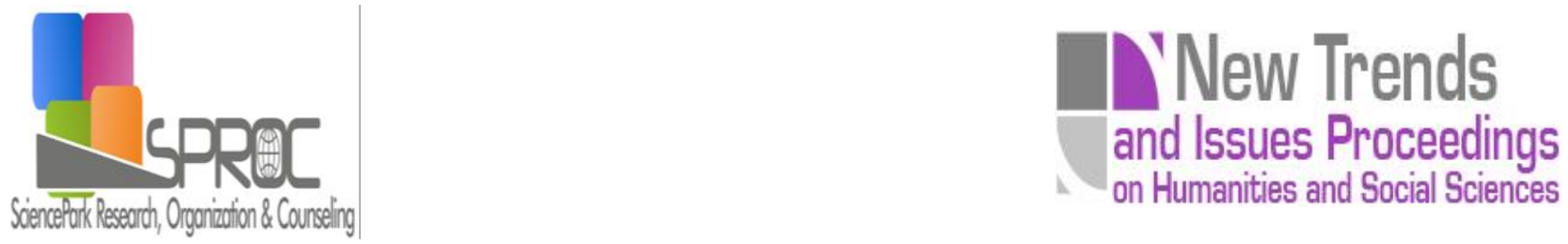

$\underline{\text { www.prosoc.eu }}$

\title{
The Role and Importance of Workshops in the Architectural Design Education; Case of "Self Made Architecture I-II"
}

Melike Orhan

Suggested Citation:

www.prosoc.eu

Abstract

Keywords: 
1. Introduction

2. Informal Education and Workshops

3. Effects of Informal Education on Architectural Design Education 
4. Self-Made Architecture I-I 


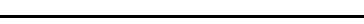

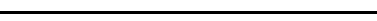


Table 1. Evaluation of Student Acquisitions After Workshop

Acquisitions 1

2

3

4

5

(less)

5. Conclusion 
References 